\title{
El nivel local en el estudio de las organizaciones campesinas. Las organizaciones de Amatán, Chiapas
}

\author{
Armando García Chiang* \\ Escuela de Altos Estudios de Ciencias Sociales, París
}

\begin{abstract}
El objetivo de este ensayo es analizar las movilizaciones campesinas en tres niveles: el nacional, el regional y el local.

A partir de una breve síntesis del movimiento campesino nacional, se aborda el caso de Chiapas a nivel regional y se presenta el caso del municipio de Amatán como ejemplo local.
\end{abstract}

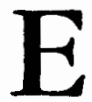
1 análisis del movimiento campesino en México ha sido, a lo largo de las últimas décadas, un tema de estudio cardinal para un número importante de académicos $\mathrm{e}$ investigadores, y los planteamientos metodológicos que se han utilizado para abordarlo, comprenden un amplio espectro; entre los cuales, conviene destacar las categorías de análisis del marxismo, la teoría de la de-

* Maestro en Estudios Regionales por el Instituto Mora; actualmente estudia el doctorado en la Escuela de Altos Estudios de Ciencias Sociales de París. pendencia y los movimientos sociales. Asimismo, el enfoque territorial que se le ha dado al estudio del mo-vimiento campesino comprende el macrorregional, expresado en los estudios de carácter nacional, el abordaje regional que comprende tanto regiones geográficas como culturales, y el de carácter microrregional repre. sentado por una cantidad importante de estudios de caso.

Sin embargo, según mi punto de vista, son escasos los trabajos que presentan una visión de conjunto de los diferentes enfoques territoria les. Por tanto, el objetivo de este en- 
sayo es hacer un análisis del movimiento campesino chiapaneco, contextualizándolo dentro del plano nacional e incluyendo un ejemplo de nivel local.

De acuerdo con ello, se aborda en forma general la historia del movimiento campesino nacional, se utiliza al estado de Chiapas como el escenario regional de ese movimiento $y$, finalmente, se accede al nivel local con el estudio de un caso particular que es el proceso de organización popular del municipio de Amatán, Chiapas.

Asimismo, conviene aclarar que este trabajo consta de dos partes: la primera de ellas expone un panorama general de las organizaciones campesinas de México, a partir de un breve esbozo histórico del movimiento que se ha generado actualmente y que presenta tanto las características principales de las organizaciones campesinas más importantes a nivel nacional, como los rasgos particulares de las organizaciones regionales chiapanecas.

En la segunda parte se expone el análisis del proceso organizativo que se ha llevado a cabo en el municipio de Amatán, donde conviven diferentes tipos de organizaciones campesinas que reflejan, en cierta medida, la situación existente en el estado, particularmente en la diócesis de San Cristóbal de las Casas, donde organizaciones campesinas surgidas de la base de la Iglesia Popular coexisten con otro tipo de organizaciones autónomas y con organizaciones estrechamente ligadas al estado.
EL NIVEL GENERAL

\section{El movimiento campesino en síntesis}

Para comprender el movimiento campesino actual de mejor manera, es necesario presentar algunos de sus antecedentes históricos. Según Armando Bartra, podemos distinguir dos grandes épocas en la lucha campesina en México: la primera, constituida por movimientos rurales decimonónicos que presentan una gran heterogeneidad, pero que podrían considerarse como manifestaciones de la resistencia campesina a la expansión de una sociedad burguesa; la segunda, conformada por el movimiento campesino que arranca con la revolución. De acuerdo con esta perspectiva, existe entre las dos un periodo que sirve como punto de inflexión y que corresponde a las dos últimas décadas del porfiriato. ${ }^{1}$

El movimiento campesino posrevolucionario tiene como escenario inicial una reforma agraria que no modifica sustancialmente la estructura económica preexistente, ya que, para el grupo sonorense que resultó triunfador en la revolución, fue una herramienta de pacificación y no un proyecto de desarrollo agrícola.

Sin embargo, en este pcriodo tuvo lugar un cambio político radical en la relación entre el Estado y los campesinos, al convertirse el Estado mexicano, a través del ejido, en el mediador entre el campesino y la tierra.

La utilización de la reforma agraria, como un proyecto de transforma-

\footnotetext{
${ }^{1}$ Bartra, Herederos, 1986.
} 
ción de la estructura económica rural, tiene lugar durante el periodo cardenista y significa un cambio, no sólo en la relación política del campesinado con el Estado, sino en la ubicación económica de un importante sector, el de los ejidatarios, quienes gracias a que pudieron disponer de tierras de riego y de zonas con agricultura de plantación, aparecen por primera vez como productores mercantiles y no sólo como reproductores de la fuerza de trabajo. ${ }^{2}$

Después del sexenio cardenista, se inicia un periodo que configura una auténtica contrarreforma agraria porque reconcentra los recursos y la tierra en las manos de la burguesía agraria por medio de políticas estatales que han dado lugar a la conformación de una estructura agraria altamente polarizada y diferenciada en su composición de clase. ${ }^{3}$

Además, de acuerdo con Flores Lúa y Sarmiento, puede decirse que en los treinta años transcurridos entre 1940 y 1970 , todas las medidas políticas citadas fueron calculadas para vincular el desarrollo agrario del país a las necesidades del crecimiento industrial. ${ }^{4}$

Asimismo, puede apuntarse que, desde 1940 hasta 1965, la agricultura mexicana cumplió satisfactoriamente las funciones que le había asignado el proyecto de industrialización que siguieron las diferentes administracio-

${ }^{2}$ Ibid., pp. 18,19.

${ }^{3}$ Autores como Flores, Paré y Sarmiento, Voces, 1988; Bartra, Herederos, 1986; Gómez, Movimiento, 1981.

${ }^{4}$ Ibid. nes gubernamentales, al crecer más rápido que la población nacional y abastecer al mercado interno durante veinticinco años, con productos agrícolas de costo relativamente bajo. Al mismo tiempo, permitió reducir las importaciones agropecuarias y obtuvo excedentes exportables, con lo que financió la importación de una parte sustancial de la infraestructura industrial. ${ }^{5}$

Este modelo de desarrollo se resquebrajó, a mediados de los años sesenta, porque se inició un proceso de deterioro del sector agropecuario, el cual podría resumirse en el agotamiento de un sector sometido a la permanente descapitalización en beneficio de la acumulación industrial; ello se tradujo en la depauperación del sector campesino pobre y medio, y es precisamente en esta evolución desigual donde se ubican las raíces estructurales de las demandas campesinas de tierra, y de mejores condiciones de trabajo y de producción. Estas demandas comienzan, a partir de la década de los setenta, a movilizar con mayor fuerza a importantes núcleos de solicitantes de ticra: jornaleros agrícolas, ejidatarios, comuneros y pequeños propietarios. ${ }^{6}$

Si bien el agotamiento estructural del sector agropecuario, como cimiento de la transformación industrial del país, se manifiesta a mediados de los sesenta con el deterioro de la producción, lo cierto es que la auténtica crisis de la economía cam-

\footnotetext{
sibid.

${ }^{6}$ Flores, Paré y Sarmiento, Voces, 1988, pp. 31,32 .
} 


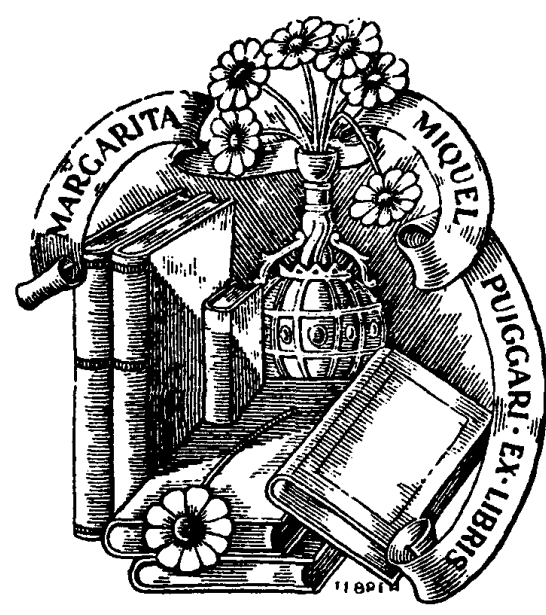

pesina se desata a principios de los setenta, durante el gobierno de Luis Echeverría.

Esta crisis, según lo expone Bartra, fue una crisis social agraria catalizada por factores coyunturales, como la disminución de los precios de los productos de exportación -algodón, café, jitomate-, una mayor necesidad de importación de granos que coincidió con un aumento de los precios internacionales de los mismos y con la configuración misma de un sector agropecuario orientado al exterior, donde el agotamiento del sector tradicional, hizo depender el abastecimiento interno de granos del mercado internacional; la capacidad de acumulación de una industria dependiente en gran medida, de los precios agrícolas bajos que permitían satisfacer las necesidades alimentarias de los obreros con una proporción pequeña de sus salarios; y finalmente, la reproducción y el crecimiento de la base industrial, supeditados a importaciones que, dada la escasa exportación industrial, se habían sustentado en el superávit agropecuario y de servicios.

Esta crisis del sector agropecuario que estallaría durante el gobierno de Luis Echeverria, se tradujo políticamente en la agudización de la lucha campesina-principalmente por la tierra-, en el deterioro de la capacidad de manipulación del Estado a través de la Confederación Nacional Campesina (CNC), y en el desarrollo de organizaciones alternativas, algunas oficialistas, como la Unión General de Obreros y Campesinos Mexicanos (UGOCM), una fracción de la Central Campesina Independiente (CCI) y el Consejo Agrarista Mexicano (CAM), y otras independientes, como la otra fracción de la CCI y múltiples organizaciones regionales.

Otro aspecto que conviene destacar es que debe diferenciarse una política agraria que durante los primeros tres años no mostró grandes cambios en relación con los regímenes anteriores, y donde la represión continuó siendo la norma generalizada para contener a los movimientos campesinos, de una segunda etapa en la que, ante el riesgo de desatar una guerra rural, esa política se sustituyó por otra en la que se intentó dinamizar la producción agropecuaria y se volvió a privilegiar un discurso agrarista.

Esta nueva política tuvo, por un lado, una expresión económica en el 
establecimiento de ejidos colectivos, en el aumento de los precios de garantía (que habían sido contenidos por años) y en la creación de instituciones como Tabamex, Inmecafé y Proquivemex que intentaron frenar el intermediarismo; por otro lado, tuvo una expresión política en la modernización de las instituciones gubernamentales y de la legislación agraria que se intentó operativizar a través de la promulgación, en 1971, de La Ley Federal de la Reforma Agraria y la Ley Federal de Aguas, y en la transformación, a fines de 1974, del Departamento de Asuntos Agrícolas y Colonización (DAAC) en la Secretaría de la Reforma Agraria.

Asimismo, en una acción tendiente a dotar de base social a estas medidas y a obtener resultados favorables para el Estado, se reorganizó el movimiento campesino oficial fortaleciendo a la CNC.

Sin embargo, para finales del periodo de Echeverria, fue evidente el fracaso de las medidas tomadas para dinamizar el campo y más aún para contener las demandas campesinas, ya que éstas provocaron, precisamente, el efecto contrario y ese periodo presidencial tuvo que enfrentar la auténtica efervescencia de un movimiento campesino que, para 1973, cobró espontáneamente un carácter nacional, al mismo tiempo que comenzó a estructurarse en organizaciones regionales.

El periodo presidencial de López Portillo se enfrentó en sus inicios con una crisis agrícola bastante grave, en donde la producción agropecuaria era decreciente y existía una situación

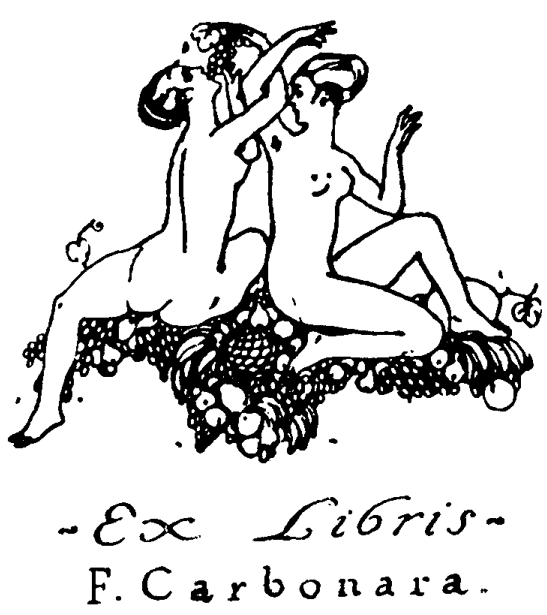

de enfrentamiento entre el Estado y la burguesia agraria, que había sido provocado por las medidas de corte populista establecidas durante el régimen anterior.

Esta crisis fue planteada por el Estado como una crisis agrícola y no como una crisis agraria o social; por ello, la respuesta del Estado fue hecha bajo un esquema eminentemente productivista, el cual atribuía la mayoría de los problemas en materia agropecuaria a la ineficiencia productiva del ejido. Desde el primer momento se planteó como objetivo principal recuperar la autosuficiencia alimentaria, y se otorgaron a la burguesía agraria todas las facilidades y la más amplia seguridad jurídica para invertir en el campo, todo esto reali- 
zado de acuerdo con la tesis de que el desarrollo agropecuario se lograría con base en las supuestas ventajas comparativas que favorecerían una orientación agroexportadora de hortalizas y ganado.

En ese sentido, un eje fundamental de la política agraria de López Portillo fue el cierre definitivo de la fase distributiva de la reforma agraria, y otro, la recuperación o el control por parte del Estado o del capital privado de las mejores tierras de los campesinos y su subordinación al proceso general de valoración del capital; puede decirse que los dos crearon el contexto para la realización de los distritos de temporal en 1977 y la estructuración en 1980, del Sistema Alimentario Mexicano (SAM) y de La Ley de Fomento Agropecuario (LFA) ? acciones que pueden considerarse como la síntesis de la política agraria del gobierno de López Portillo al ejemplificar el énfasis puesto en las cuestiones de productividad y el abandono del discurso agrarista.

Esa tendencia se agudizó durante el sexenio de Miguel de la Madrid, debido a que, en ese periodo, tuvo lugar la implantación del Programa de Reordenación Económica Inmediata (PIRE), cuyas características, que reflejaban un tipo de proyecto tradicionalmente asociado a las políticas monetaristas del Fondo Monetario Internacional, tuvieron como objetivo disminuir las presiones inflacionarias reduciendo la demanda y el salario real. También se puso en práctica el Plan Nacional de Desarrollo (PND)

\footnotetext{
${ }^{7}$ Flores, Paré y Sarmiento, Voces, 1988.
}

donde se recalcó que la reorientación del sector agrario se inscribía en el marco más amplio de una estrategia de desarrollo rural integral que implicaba la incorporación de políticas de producción y de organización del campo y una política de atención a las necesidades de bienestar de la población. Dentro de esos lineamientos, se pretendió otorgar seguridad jurídica a las diversas formas de tenencia de la tierra e impulsar la organización de los productores.

Estos planteamientos tuvicron relevancia en el movimiento campesino porque colocaron a la lucha por la tierra dentro de la legalidad y le dieron la posibilidad de negociación. Sin embargo, las reformas constitucionales que se realizaron en ese periodo y que elevaron a rango constitucional la propiedad privada, al mismo nivel de legalidad que el ejido y la de la comunidad, estuvieron dirigidas a la legalización de la propiedad existente y no a promover la distribución, por lo que en general, puede decirse que el resultado de la política agraria del sexenio delamadridista fue el de crear las bases de las reformas radicales en materia agraria que se instrumentarían en el siguiente periodo presidencial.

El siguiente sexenio se inició en medio de fuertes cuestionamientos acerca de la legalidad de la clección, y pasó por un periodo de consolidación ante la opinión pública. La promoción de concertaciones y acercamientos crearon las condiciones que permitieron, en 1991, aprobar las reformas al artículo 27 constitucional, y crear con ello las condiciones jurí. 
dicas necesarias para establecer una agricultura eminentemente comercial.

Este evento que dio por concluido el reparto agrario, causó un gran descontento entre las organizaciones campesinas independientes y aun entre las oficiales y oficialistas, al afectar en sus bases mismas los planteamientos agrarios de la revolución.

En el último año del sexenio de Carlos Salinas de Gortari, justo en el momento en que los círculos oficiales celebraban el anhelado arribo de nuestro país al mundo desarrollado, es cuando irrumpe en el escenario nacional el Ejercito Zapatista de Liberación Nacional, y con él, las reinvindicaciones por la tierra que se pretendían superadas.

Según Beatriz Canabal, la irrupción zapatista en un año electoral marcó de manera inmediata a ciertos giros que se dieron en materia de política agraria y de convergencia social, como fueron la gran cantidad de promesas de ampliar el beneficio social a zonas marginadas y el acercamiento a organizaciones agrarias, tanto de todo el país como de Chiapas.

Esas condiciones cambiarían sustancialmente con el asesinato del candidato del PRI, Luis Donaldo Colosio, y con la adopción, por parte del nuevo candidato presidencial, de una actitud más agresiva hacia las expresiones disidentes y una menor disposición al diálogo con las fuerzas zapatistas y con el movimiento campesino en general. Una vez elegido presidente, Ernesto Zedillo lanzó un programa contra la pobreza y otro para el agro que expresa la continuidad del modelo neoliberal impuesto por su antecesor, en el cual se utilizarían con mayor intensidad instrumentos de control social como PROCAMPO y Pronasol. $^{8}$

De esos instrumentos, sólo ProCAMPO se mantuvo vigente durante los dos primeros años del sexenio zedillista, mientras que aparecían nuevos programas como la Alianza para el Campo, a través del cual el Estado pretendería ayudar a un gran número de productores agrícolas, los cuales se han visto imposibilitados de pagar las deudas contraídas con la banca nacional.

\section{Organizaciones campesinas de carácter nacional}

Para acercarse a la historia de las organizaciones campesinas oficiales y oficialistas, es necesario señalar que la creación de la CNC representa la culminación de un proceso por el que se intentó crear una central campesina unitaria. Ese proceso, donde el Estado mexicano, a través del Partido Nacional Revolucionario, emprendió la tarea de unir las ligas campesinas estatales y regionales, culminó en 1938 con la creación de la Confederación Nacional Campesina (CNC), la cual se integró directamente al Partido de la Revolución Mexicana (PRM) que había sustituido al PNR.

En los años que siguieron al periodo cardenista, el congelamiento de las acciones agraristas y los virajes en materia de política agrícola, crearon problemas en la CNC. Al sentir que la

"Canabal, "Movimiento", 1995, p. 3 
Central no los representaba realmente, un importante sector de sus miembros se separó y, entre 1947 y 1948, formó la Alianza de Obreros y Campesinos (AOC). Esta alianza estuvo compuesta por contingentes obreros dirigidos por Vicente Lombardo Toledano y por los grupos campesinos que salieron de la CNC. En el mismo periodo se fundó la Confederación Unica de Trabajadores (CUT), que se uniría en 1949 a la AOC para conformar la Unión General de Obreros y Campesinos de México (UGOCM).

A partir de 1951, la UGOCM se convirtió en una organización netamente campesina, al no poder incidir legalmente en cuestiones laborales relacionadas con los obreros; sin embargo, su independencia y su fuerza en el norte del país siguió preocupando al Estado, quien favoreció una división en su seno; estas división dio lugar a tres organizaciones diferentes que conservaron el nombre de UGOCM.

Durante el auge del movimiento campesino en la década de los sesenta, destaca la formación de la Central Campesina Independiente (CCI), organización que planteó la necesidad de una reforma agraria radical y en cuyo proceso de integración destacó la influencia de Lázaro Cárdenas.

La CCI atacada desde sus orígenes por el Estado, representó el intento frustrado de renovación del movimiento campesino organizado oficial u oficialista; a sólo un año de su creación experimentó su primera ruptura, ya que en el año de 1964, una de sus fracciones acompañó en su expulsión a su lider Danzós Palomino; se mantuvo ligada al PCM y algunos años después, en 1975, durante su III Congreso Nacional Ordinario, se transformó en la Central Independiente de Obreros y Campesinos (CIOAC); la otra fracción conservó la denominación de CCI y se incorporó al PRI en 1970.

De acuerdo con Clarisa Hardy, en 1973, ante la dificultad de controlar a las centrales campesinas que tenían un radio de acción nacional y como un intento de controlar el movimiento campesino, se crearía el Congreso Agrario Permanente (CONPA), ${ }^{9} \mathrm{y}$ al año siguiente, ante la inoperabilidad del CONPA, se haría un compromiso programático de acción de todas las centrales que lo firmaron, el cual es conocido como el Pacto de Ocampo, y con él, se intentaría dar un apoyo unificado a la política agraria y agrícola del gobierno.

Durante este periodo, los actores principales de la lucha en el campo, fueron los jornaleros y los campesinos pobres de las regiones agrícolas atrasadas, quienes durante el periodo de Luis Echeverría, fueron objeto de un discurso agrarista y neopopulista que, en la práctica, sólo agravó los problemas del sector agropecuario; durante el sexenio de López Portillo tuvieron que soportar además los embates de un gobierno que dio por cancelado el reparto agrario. ${ }^{10}$

Ante esa situación, la reacción de los numerosos grupos campesinos en lucha fue la de avanzar en procesos de unidad regional y nacional que les

${ }^{9}$ Hardy, Estado, 1984.

${ }^{10}$ Bartra, Herederos, 1988; Canabal, "Movimiento"; Flores, Paré y Sarmiento, Voces, 1988. 
permitieran enfrentar las políticas gubernamentales. Un resultado de esos procesos fue la conformación, en octubre de 1979, de la Coordinadora Nacional Plan de Ayala, la cual aglutinó desde su creación a los solicitantes de tierras, ejidatarios y comuneros despojados de las suyas o defensores de las que les quedan.

A partir de la década de los ochenta, con el agravamiento de la crisis económica, la situación cambiaría y, desde ese momento hasta la irrupción del EZNL en la vida nacional, serían los campesinos medios quienes asumirían el papel de actores principales del movimiento campesino.

Puede decirse asimismo que, a partir de los setenta, cambiaría la estrategia de movilización y, si bien durante el primer periodo las demandas fueron diversas y heterogéneas (tierra, servicios, crédito, alto a la represión, defensa de recursos naturales), la coordinación amplia y estable fue muy difícil: las acciones emprendidas generalmente fueron protestas, denuncias, peticiones aisladas y, lo más común, la utilización de un lenguaje contestatario; lo cierto es que en el siguiente periodo, que abarca la década de los ochenta, las demandas continuarían siendo heterogéneas y dispersas, pero las acciones de protesta se plantearían objetivos más concretos, como negociaciones con autoridades, aumento de precios de garantía, afectaciones de tierra en áreas bien determinadas y propuestas de las organizaciones campesinas relacionadas con la planificación del sector: el discurso se volvió más propositivo y la confrontación fue cedien do su lugar a una cierta concertación. ${ }^{11}$

De acuerdo con ese nuevo contexto, la Coalición de Ejidos de los Valles del Yaqui y Mayo, junto con otras organizaciones de varios estados del país, iniciaron un proceso de convergencia que culminó con el surgimiento, en 1985, de la Unión Nacional de Organizaciones Regionales Campesinas Autónomas (UNORCA), inaugurando así una nueva estrategia dentro del movimiento campesino acorde con una heterogeneidad política y con una diversidad de intereses, en que se combinan formas de acción y de protesta radicales, como toma de oficinas y bloqueos de carreteras; con acciones de denuncia, gestoría y protesta ante las autoridades.

Esa nueva estrategia se mantuvo dentro del movimiento campesino durante todo el sexenio de Carlos Salinas de Gortari, aunque este lapso también puede ser considerado como un periodo de reflujo del movimiento campesino, en el que los vínculos entre las diferentes organizaciones campesinas tendieron a ser menos fuertes.

Por su parte, el gobierno de Ernesto Zedillo contempló la aparición, en el escenario del movimiento campesino, de la Unión Nacional de Productores Agropecuarios, Comerciantes y Prestadores de Servicios, El Barzón, la cual surgió como una movilización de campesinos de medianos recursos que se oponían a la política de embargos que la banca comercial intentaba ejercer contra ellos por la falta

${ }^{11}$ García, "Estrategia", 1994. 
de pago de los créditos que habían solicitado y que, en un lapso muy breve, se convirtió en un movimiento aglutinador de clientes de la banca descontentos con la política de la misma o que habían caído en la llamada cartera vencida.

\section{El movimiento campesino a nivel regional: las organizaciones de Chiapas}

En este apartado se abordará la dimensión regional chiapaneca del movimiento campesino, a través de sus organizaciones más representativas. Para ello, y como un paréntesis introductorio es conveniente señalar que: es casi un lugár común afirmar que el ascenso del movimiento agrario en Chiapas se remonta a 1974, año en que se realizó el Cogreso Indígena promovido por la diócesis de San Cristobal de las Casas para celebrar los 500 años del nacimiento de fray Bartolomé de las Casas ${ }^{12}$ ya que, durante su transcurso, las agrupaciones campesinas participantes encontraron un foro para expresarse y más adelante, al apropiarse de la estructura que lo había convocado, un espacio para manifestarse.

Fue así como surgió un Congreso Indígena que, desde el principio, se vio sometido a intentos de cooptación y mediatización por parte del Estado, como la creación de otro Congreso Indígena en 1975, bajo el control de la CNC; éste, a pesar de su corta duración, abrió los espacios que permitie-

${ }^{12}$ Guillén, "Estructuras", 1994, p. 266. ron impulsar un movimiento campesino chiapaneco agrupado alrededor de la lucha por la tierra.

En este contexto nacerían diversas agrupaciones campesinas, algunas de carácter regional y muchas otras de carácter municipal y local, entre las cuales existen dos tendencias principales: los movimientos que han incorporado reivindicaciones adicionales a la de la tenencia de la tierra, como el acceso a los mercados o la creación de sindicatos, y los que siguen siendo eminentemente agrarios. ${ }^{13}$

Según Diana Guillén, en el primer caso estaría la Central Independiente de Obreros y Campesinos (CIOAC), cuya presencia es importante en los municipios de Simojovel, Huitipán y el Bosque; y la Unión de Uniones y Grupos Solidarios de Chiapas que agrupa comunidades tzeltales, tojolabales, choles, tzotziles y ladinas ubicadas en diez municipios de las regiones Selva, Norte y la Sierra Madre, y en el segundo caso estaría la Organización Campesina Emiliano Zapata (OCEZ), cuyo radio de acción abarca comunidades de los Altos, del Centro, de la región Norte y de la Fronteriza. ${ }^{14}$

Por otro lado, la misma autora indica que, en los últimos veinte años, lo que ha caracterizado al paisaje chiapaneco es la emergencia de inume-

${ }^{13}$ Ibid.

${ }^{14}$ Con respecto a la actividad de la cIOAC en Huitipán y Simojovel, de la Unión de Uniones en las zonas con origen étnico tzeltal y chol, y de la ocez en el municipio de Venustiano Carranza conviene consultar los trabajos de Neil Harvey, "La lucha", 1990, y "La unión", 1991. 


\section{SECUENCIA}
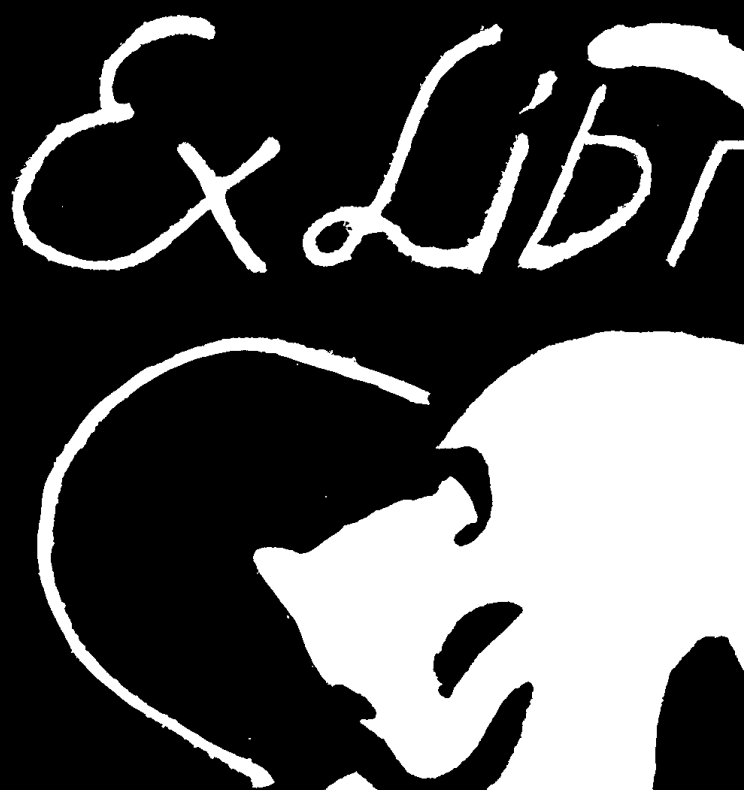
rables movimientos que han propiciado el surgimiento de organizaciones tanto locales y municipales como regionales. Entre ellas señala al Consejo Nacional de Pueblos Indígenas, con influencia en Bachajón y en San Cristóbal de las Casas, la Coordinadora Campesina Revolucionaria Independiente (CCRI), con una reducida base en el Soconusco y en el municipio de Jiquipilas, y la Unión Nacional de Trabajadores Agrícolas (UNTA), filial del PRCRN, con amplia influencia en Chenalhó, Pantelhó, Sitalá, Yajalón y Petalcingo.

Por otro lado, pero en la misma línea, debe apuntarse que también durante la década de los ochenta y lo que va de ésta, han surgido agrupaciones que exploran nuevas formas de organización y convergencia estatal, de construcción de alternativas pro. ductivas, de acceso a mercados nacionales e internacionales y de vínculo con el movimiento campesino nacional. Éste sería el caso de los organismos ligados con la UNORCA a través de la Convergencia de Organizaciones Campesinas en el estado Chiapas (COCEH); de las empresas comercializadoras sociales que agrupan a pequeños cafeticultores; de las organizaciones que trabajan en el desarrollo de tecnologías para la producción de cultivos orgánicos, como las que integran el Frente de Organizaciones Indígenas Independientes de Pequeños Productores y Comercializadores Orgánicos (FOIPCO); $\mathrm{y}$, en un plano de mayor trascendencia política y social, de la Coordinadora XI' Nich, que en marzo de 1992 logró aglutinar a organizaciones campesinas indígenas pro- venientes de 18 municipios chiapanecos. ${ }^{15}$

Finalmente, debe destacarse la irrupción en el escenario chiapaneco del Consejo Estatal de Organizaciones Indígenas y Campesinas de Chiapas (CEOIC), el cual aglutinó desde su creación a 280 organizaciones campesinas, tanto de las consideradas como independientes como de las oficiales y oficialistas.

Sin embargo, la gran fuerza que tuvo el CEOIC se fue diluyendo, debido en parte a pugnas internas y en parte a la acción gubernamental que fomentó la división entre las organizaciones que lo integraban, por lo que, a mediados de 1995, su importancia decreció notablemente, hasta el punto de poder decirse que su papel como interlocutor gubernamental fue ocupado por la Asamblea Democrática del Pueblo Chiapaneco (ADEPECH).

\section{EL NIVEL LOCAL: LAS ORGANIZACIONES CAMPESINAS AMATECAS}

Cuando se eligió al municipio de Amatán ${ }^{16}$ como lugar de estudio, la decisión se basó, entre otras cosas, en que confluyen en él diferentes tipos de organizaciones campesinas que reflejan, en cierta medida, la situación exis-

15 Peña, "Tercer", 1994.

${ }^{16}$ El municipio de Amatán está situado en el noroeste del estado de Chiapas, en la frontera con Tabasco, pertenece a la región geográfica denominada Sierra Norte y tiene una extensión de $109.30 \mathrm{~km}^{2}$ siendo sus coordenadas extremas $92^{\circ} 45^{\prime}$ y $92^{\circ} 56^{\prime}$ longitud oeste; $17^{\circ} 18^{\prime}$ y $17^{\circ} 29^{\prime}$ latitud norte. 
tente en el estado, particularmente en la diócesis de San Cristobal de las Casas.

La existencia de organizaciones campesinas autónomas, surgidas de la base de la Iglesia Popular y de organizaciones estrechamente ligadas al Estado, confieren a este municipio un interés especial para analizar los procesos que se desarrollan en el mismo. Con el objetivo de diferenciar a las organizaciones locales, conviene aclarar que las que tienen influencia de la tendencia religiosa conocida como Teología de la Liberación son la Asam. blea Zoque y la Sociedad de Solidaridad Social La Flor de Amatán; y aquellas en cuyo proceso de integración influyó directamente el Estado son la Unión de Ejidos, la Unión Ganadera, la Sociedad de Solidaridad Social, El Progreso de Amatán y la Sociedad Cooperativa La Región Marginada; finalmente debe apuntarse la presencia del Frente Cívico de Amatán, que puede ser considerado como una organización surgida en forma netamente coyuntural en un momento de efervescencia política y que aglutinó en su momento a integrantes de diferentes asociaciones, pero que no pertenece a ninguno de los dos grupos en que se ha clasificado a las organizaciones amatecas.

Para realizar una comparación entre las organizaciones que emergieron de un proceso en que intervino la Iglesia católica y de otro en que lo hizo directamente el Estado, fueron escogidas las S.S.S. La Flor de Amatán y El Progreso de Amatán porque se considero más adecuado comparar dos similares y porque cada una de ellas muestra los diferentes procesos que se pretenden analizar. ${ }^{17}$

\section{La Sociedad de Solidaridad Social La Flor de Amatán}

Como introducción a este apartado conviene anotar que la historia de la Sociedad de Solidaridad Social "La Flor de Amatán" está intimamente ligada a un proceso local de organización popular cuyos antecedentes se remontan al año de 1930, cuando fueron fundados los ejidos de Amatán y San Antonio en terrenos que pertenecían a la finca "El Escalón".

De hecho, esta asociación puede ser considerada como una expresión organizativa del movimiento campesino local. Sus antecedentes inmediatos pueden ubicarse en la década de los sesenta, hacia 1966, cuando comenzó en la parroquia de Amatán un proceso de concientización de la comunidad, basado en una mayor integración de la población a las actividades eclesiásticas, a través de cursos bíblicos en los que se comenzaba a reflexionar acerca de lo que se consideraban posturas liberadoras en el Evangelio.

\footnotetext{
${ }^{17}$ Como nota aclaratoria conviene señalar que las sociedades de solidaridad social son una figura jurídica que se constituye con un patrimonio de carácter colectivo, cuyos socios deberán ser personas físicas de nacionalidad mexicana, en especial ejidatarios, comuneros, campesinos sin tierra, parvifundistas y personas con derecho al trabajo, que destinen una parte del producto del mismo a un fondo de solidaridad social y que podrán realizar actividades mercantiles. Leyes, Sociedades, 1988.
} 
Trece años más tarde, llegaron al municipio las religiosas de la Orden de San José de Lyon, quienes permanecerían en él por más de diez años; con su llegada, la organización comunitaria eclesial ${ }^{18}$ recibiría un mayor impulso y el enfoque que se le daría a Ia formación religiosa de los catequistas se volvería concientizador y crítico de la situación de pobreza y explotación que imperaba y sigue imperando en el municipio.

Con la erupción del volcán Chichonal en 1982, se apoyarían en Amatán los primeros intentos de trabajar en cooperativas, tratando de aprovechar, de la mejor manera posible, la ayuda enviada a los damnificados desde el Distrito Federal. Estos intentos resultarían más bien fallidos, debido a la poca o nula experiencia de la población en este tipo de actividades, pero contribuirían al proceso de organización popular, al sentar las bases de un trabajo en común y organizado.

En la construcción de este proceso, 1984 sería un año importante. Se notaba ya cierta motivación de la gente para enfrentar la injusticia y la represión, que eran la norma en el municipio; un ejemplo de ello es que la comunidad de Reforma y Planada co-

\footnotetext{
${ }^{18}$ En este punto debe aclararse que la Iglesia católica entiende por comunidad eclesial a sus feligreses, quienes representaban en 1994 el $43.51 \%$ del total de población según el sNIM; sin embargo, para los efectos de este trabajo se considerará como comunidad eclesial a la llamada de base, la cual está integrada por personas ligadas al culto católico que participan en el proceso de organización popular.
}

menzaría una movilización, finalmente exitosa, para obtener tierras. ${ }^{19}$

Tres años después se realizaría otra toma de tierras pertenecientes a la finca El Escalón. En ese año surgiría también una lucha municipal que buscaba la destitución del edil. Esta lucha, encabezada por comisariados ejidales, contó con el apoyo de la parroquia ${ }^{20}$ y fue la situación coyuntural que agrupó el descontento de la población y sentó las bases para el surgimiento de un movimiento popular, cuya primera expresión organizativa fue el Comité de Defensa de la Libertad Indígena y Derechos Humanos (CODELIDECH); éste, desde su nacimiento, comenzaría a jugar un papel importante en la historia municipal al unir y organizar a los comisarios ejidales para enfrentarse a una autoridad local de carácter eminentemente represivo. ${ }^{21}$ Esa primera actuación del comité se iniciaría durante los últimos días de 1987 y culminaría en marzo de 1988 con la destitución del alcalde.

El siguiente año, ante las limitaciones legales para establecer, como expresión organizativa, un comité de defensa de derechos humanos y con el objetivo de darle un mayor impulso a las actividades económicas, los integrantes del CODELIDECH crearían el 7 de abril de 1989, la Sociedad de Solidaridad Social "Unión de Cafeticultores del Norte de Chiapas", la

\footnotetext{
${ }^{19}$ Entrevista directa con un poblador de la comunidad Reforma y Planada, Amatán, Chis., julio, 1992.

${ }^{20}$ Entrevista directa, Amatán, abril, 1992.

${ }^{21}$ CODELIDECH, Ponencia, 1989.
} 
cual, conseguiría su registro dos años más tarde con el nombre de La Flor de Amatán.

Como organización campesina independiente, ésta tiene un rasgo distintivo que la hace diferente de la mayoría de las organizaciones campesinas de su tipo. Es el de haber salido de las filas de las Comunidades Eclesiales de Base, lo cual le confiere una estructura organizativa donde las decisiones importantes son tomadas en asambleas de representantes, y donde su dirigencia, surgida de su propia base, continúa recibiendo un acompañamiento religioso que resalta su compromiso de crear, como cristianos, una sociedad más justa ${ }^{22}$ la adopción de dicha postura constituye, de forma ideal, uno de los requisitos indispensables que debe tener el comité directivo y, en caso de alcanzarse, ésta podría favorecer que las cosas fueran realmente contempladas desde una perspectiva de fe, fraternidad y compañerismo, que pudiera evitar que, en un momento determinado, la dirigencia adoptara actitudes contrarias a las de la mayoría y dejara de ser representante de los intereses de la organización.

En este punto, es conveniente anotar que la máxima autoridad dentro de La Flor de Amatán es una Asamblea General que se reune dos veces al año. En ella se eligen, cada tres años, un comité ejecutivo, uno de vigilancia $y$ otro de finanzas; se presentan en ella las personas que han sido nombradas

\footnotetext{
${ }^{22}$ Este compromiso es conocido en los sectores ligados a la Iglesia católica como de servicio a la comunidad.
}

en cada comunidad como sus representantes en las asambleas mensuales de delegados, y se realiza un balance de las actividades efectuadas.

El Comité Ejecutivo está integrado por un presidente, un secretario y un tesorero, quienes pese a dedicar una parte considerable de su tiempo a las tareas propias de su cargo (como la participación en las asambleas del Fondo Regional de Solidaridad, las reuniones con los asesores técnicos o los eventos organizados por la presidencia municipal), no reciben remuneración económica y una de las explicaciones a su disposición para realizar las tareas que les han sido encomendadas es el hecho de que sienten el compromiso, como cristianos, de luchar por construir una nueva sociedad. Ello no necesariamente significa que ésta sea una organización religiosa, sin embargo, su mismo origen en las comunidades eclesiales de base $y$ el hecho de que sus miembros tengan fe en la palabra de Dios, otorga a la organización una idea de trascendencia, de ir más alla de la resolución de los problemas inmediatos.

Es con base en el compromiso y en la idea de trascendencia que sienten sus integrantes que La Flor de Amatán busca alternativas para dar una respuesta integral a las necesidades de la comunidad. Entre ellas debe destacarse la comercialización, a través de la Unión de Comunidades Inclígenas de la Región del Istmo (UCIRI) -la que cuenta con acceso al mercado europeo de café orgánico-, del café que producen los integrantes de la organización y de la producción en la parcela de la escuela técnica de miel orgánica. 
En este punto cabe aclarar que café orgánico es la denominación de un café cuyo proceso de elaboración requiere de más trabajo manual, ya que no pueden utilizarse elementos químicos, como herbicidas o fungicidas, además de que su control de calidad debe ser mucho mayor que el del café normal. Por otro lado, cabe también destacar que, su proceso de comercialización, al ser un producto especializado, requiere de una cierta infraestructura (un centro de acopio, camiones para transportarlo, aparatos para medir el porcentaje de humedad) que se encuentra fuera del alcance de cualquier campesino minifundista y sólo accesible para asociaciones. Por tanto, debe destacarse que la producción de café orgánico va mucho más allá de una unión campesina en busca de un mejor precio para su producto, e implica toda una reconversión productiva y un indispensable proceso organizativo.

En cuanto a la reconversión productiva es destacable el hecho de que, la producción de cultivos orgánicos, lleva consigo un cierto retorno a formas tradicionales y más racionales de explotar la tierra: al desechar la aplicación de elementos químicos; al requerir el uso de abonos naturales; al implicar la construcción de pequeñas obras que eviten la erosión -como terrazas que detengan el deslave de suelos-, y al requerir de un sombreado natural que conlleva el empleo de árboles frutales como el plátano o de maderables como el cedro, la caoba o el bojón, con los cuales un cafetal normal se convierte en un verdadero policultivo.
Por lo que respecta al señalamiento de que la producción de café orgánico conlleva indispensablemente un proceso organizativo, debe tomarse en cuenta que, sólo a través de él, es posible que campesinos minifundistas puedan acopiar toneladas de café desde comunidades lejanas, en las que el único medio de acceso es una vereda de terracería, y después en. viarlas hasta Oaxaca, donde se localizan las instalaciones de UCIRI.

Otro ejemplo de las características organizativas propias de la Flor de Amatán y de su búsqueda de alternativas de solución integral, es un proyecto que ésta impulsa desde 1991, y que consiste en la creación de una Escuela de Oficios, en donde los alumnos pueden completar también una educación secundaria adaptada a la realidad del municipio y en la cual se forman los futuros técnicos de la organización. Este proyecto de Escuela comenzó sus actividades mediante un convenio firmado con el Instituto Nacional de Educación para los Adultos (INEA); sin embargo, a pesar de estar en funcionamiento desde hace más de tres años y de apoyar a la población local como escuela secundaria técnica, aún no cuenta con el reconocimiento ni con el apoyo oficial.

En cuanto a la participación de la organización en el contexto regional, es conveniente señalar que, en el año de 1991, La Flor de Amatán fue aceptada como miembro del Fondo Regional de Solidaridad, con sede en Ixtacomitán, del cual obtuvo un crédito para acopio y comercialización de café, que permitió que, por primera vez en mucho tiempo, sus socios no 
tuvieran que vender su producto a los intermediarios antes de la cosecha, sino que pudieran comercializarlo a un mejor precio.

Un aspecto destacable en lo que respecta al Fondo Regional de Solidaridad con sede en Ixtacomitán, es que, de todas las organizaciones campesinas que participan en dicho fondo, La Flor de Amatán es la única organización que ha sido capaz de cum. plir, dentro de los plazos estipulados, los créditos que le han sido otorgados.

Este hecho puede ser explicado, si se toma en cuenta que, una de sus características como organización, es que sus miembros participan en ella con metas que van más allá de unirse para poder ser sujetos de crédito; por tanto, el carácter de dicha asociación no es coyuntural ya que tienen un proyecto a futuro o, cuando menos, una idea utópica de lo que quieren lograr en él, lo cual permite suponer que, a pesar de los numerosos errores cometidos en sus proyectos productivos, la organización es una alternativa de desarrollo para la comunidad.

No obstante sus avances como organización campesina, debe anotarse que, en las elecciones para alcalde llevadas a cabo en 1995, la organización no pudo consolidar una posición como fuerza política local, ni su candidato alcanzar la presidencia municipal. Este proceso electoral, donde la inequidad de la relación entre las autoridades municipales y el Partido Revolucionario Institucional volvió a ponerse de manifiesto, demostró también que todas las organizaciones campesinas están expuestas al divisionismo y que, en este caso particular, di- ferencias personales entre los miembros de su agrupación, impidieron la elección de un edil surgido de las filas de una organización popular independiente.

\section{"El Progreso de Amatán" o la bistoria de cómo el INI entiende la organización campesina ${ }^{23}$}

Los orígenes como organización de la Sociedad de Solidaridad Social "El Progreso de Amatán" pueden situarse en la toma de tierras realizada por campesinos amatecos en el año de 1987. A partir de esa acción, ya mencionada en el apartado anterior, puede decirse que ésta surgió de un movimiento campesino local que derivó,. por un lado, en la creación de una organización campesina autónoma; y por otro, en la formación de varios grupos de solicitantes de tierras.

Uno de estos grupos, integrado por habitantes del ejido de Amatán, al obtener, a principios de 1990 , una resolución de ampliación ejidal favorable, se establecieron en el poblado conocido como Nuevo Amatán.

Aparentemente, esta acción era el primer paso para solucionar los problemas de tierra locales porque implicaba el reconocimiento de la validez de las demandas campesinas; $\sin \mathrm{em}$ bargo, al no ser definidos con claridad los límites de su dotación, los problemas con otros grupos de solici-

${ }^{23}$ La reconstrucción del proceso que dio origen a esta organización, se hizo con base en entrevistas directas a miembros de su comité directivo. Las entrevistas fueron realizadas en agosto de 1994. 
tantes se agravaron, y derivaron en la destrucción mutua de cosechas y en ataques físicos en contra de los integrantes de los grupos rivales.

Ante esa situación, algunos de los campesinos que habían sido oficialmente dotados de tierras, optaron por regresar en el año de 1991 a la cabecera municipal y buscar otras alternativas para subsistir. En esa búsqueda solicitarían su ingreso a La Flor de Amatán atraídos por el precio del café que ésta había obtenido para sus socios; empero, al no llenar requisitos de ingreso, tales como el compromiso de participar en las asambleas de la organización, de construir 500 terrazas cada año, de pagar a tiempo sus obligaciones financieras y de aceptar . financiar, con una parte de sus ganancias, los gastos operativos de la comercialización del café, ${ }^{24}$ decidieron crear una organización propia.

Según declaraciones de algunos integrantes de su comité ejecutivo, el proyecto de hacer una nueva agrupación recibiría, desde un principio, un gran apoyo de autoridades de instituciones como el Inmecafé y el INI, las que los alentaron a crearla con la promesa de intervenir en su favor a la hora de lograr el registro oficial.

La nueva organización obtuvo su inscripción en el padrón de organizaciones campesinas con el nombre de Sociedad de Solidaridad Social "El Progreso de Amatán" y, desde sus inicios, se vio beneficiada con el apoyo del director del Centro Coordinador Indigenista Zoque, localizado en Ixtacomitán, Chiapas.

\footnotetext{
${ }^{24}$ S. de S.S. "La Flor", "Requisitos", 1991.
}

Ese apoyo se tradujo en la autorización de un proyecto de acopio de café y otro de producción de frijol. Una baja en los precios internacionales del café y la aparición de una plaga que afecta al cultivo de frijol impidieron el correcto desarrollo de tales proyectos y, al serles requerido por parte del INI, el balance económico de estos proyectos, sus integrantes se vieron obligados a reconocer que no podían pagar los créditos contratados en el plazo estipulado. ${ }^{25}$

No obstante el revés sufrido por la nueva organización (que podría ser atribuido a circunstancias externas, aunque también influyeron cuestiones internas, como la falta de apoyo técnico o de visión para vender el café antes de que bajara su precio) y aun cuando existían indicios claros de que los aprobaría, el INI decidió autorizar otro proyecto que precisó de una inversión considerable y que consistió en la instalación de un beneficio de café que requería de la compra de un terreno, así como de la maquinaria necesaria para procesarlo.

Este proyecto, después de un año de trabajo, no parece tener posibilidades de éxito. Según un miembro del comité ejecutivo de El Progreso de Amatán, su fracaso se ha debido a la falta de apoyo técnico por parte del INI, según sus propias palabras:

\footnotetext{
${ }^{25}$ En este aspecto es conveniente aclarar que "La Flor de Amatán" tenía acceso al mercado internacional de café orgánico y que no tenía un proyecto de producción de frijol de gran escala, por tanto, estos hechos no la afectaron en forma directa.
} 


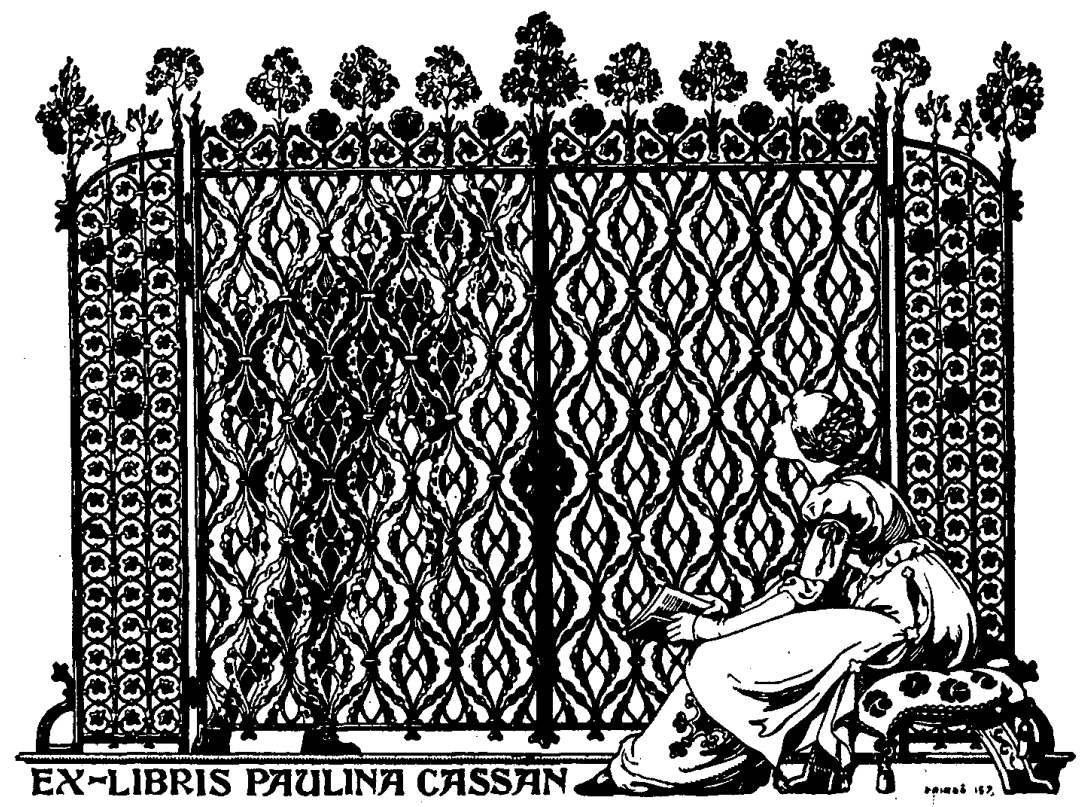

La asistencia para la producción que nos ha brindado el INI ha sido insuficiente; nosotros no queremos un técnico que esté aquí todos los días, pero sí por lo menos cada dos semanas. La gran diferencia con La Flor de Amatán es que ella tiene sus propios ingenieros y asesores $y$ por eso sus proyectos no fracasan. Ahorita nosotros tenemos muchos problemas como organización y tenemos que aceptar que estamos un poco fracasados. ${ }^{26}$

La difícil situación por la que atraviesa El Progreso de Amatán es, desde una perspectiva personal, el resultado de una asociación que se formó

\footnotetext{
${ }^{26}$ Entrevistas directas con el comité ejecutivo de la S. de S.S. "El Progreso de Amatán", Amatán, Chiapas, agosto 1994.
}

con un carácter coyuntural ante la necesidad que tenía un grupo de campesinos de organizarse para poder ser sujetos de crédito. Por tanto, su creación no fue producto de un proceso de organización popular que culminara con la formación de una agrupación campesina, sino una consecuencia de la tendencia gubernamental a fomentar la fundación de grupos campesinos controlables. desde el Estado, a través de los cuales las instituciones ligadas al campo puedan justificar su existencia y en las que no se valora si los campesinos que las integran tienen una idea definida acerca de lo que pretenden alcanzar como organización. Esta línea tiencle a favorecer procesos organizativos encabezados por personas con presencia 
moral dentro de la comunidad, ya sea porque se las reconozca como líderes en las tomas de tierras o por su participación en actividades políticas; pero a diferencia de lo que ocurre con La Flor de Amatán, el comité ejecutivo de El Progreso de Amatán no siente un compromiso de servicio con sus compañeros de agrupación.

A este respecto, conviene apuntar que, por lo menos en la región Sureste del país y en los últimos años, la atención gubernamental se ha enfocado hacia las organizaciones y no hacia los productores individuales. Desde 1989, y por medio de instituciones como el Instituto Nacional Indigenista, El Fondo Regional de Solidaridad o la Secretaría de Desarrollo, el Estado ha declarado que no existirá ningún tipo de apoyo para personas individuales y que éste será canalizado por completo a través de organizaciones como uniones de ejidos, asociaciones rurales de interés colectivo, sociedades de solidaridad social y sociedades cooperativas.

Esta política gubernamental puede ser considerada como una nueva forma de control del movimiento campesino, que el gobierno estableció durante el sexenio pasado ante el desgaste de la CNC como gestora, aun dentro de las organizaciones oficialistas.

En esa forma de control, que se operativizó mediante los Fondos Regionales de Solidaridad, se da una cierta autonomía a las asociaciones campesinas, ya que las decisiones sobre qué proyectos deben apoyarse, son tomadas por un comité directivo regional integrado por miembros de las propias organizaciones; sin em- bargo, al conservar el Estado el derecho de veto a través del INI, éste es quien realmente decide a cuáles agrupaciones se apoya. Asimismo, es el propio INI, mediante sus equipos técnicos, quien decide la viabilidad de los proyectos y el apoyo técnico que requieren.

El apoyo distintivo por medio de los Fondos Regionales de Solidaridad, tiende a brindarle uno mayor a las organizaciones oficiales y oficialistas y a negarlo o dificultarlo a las autónomas. Como ejemplo de esta afirmación, puede utilizarse el hecho de que a La Flor de Amatán le tomó cerca de un año obtener la autorización para llevar a cabo el primer proyecto que presentó al Fondo Regional de Solidaridad, consistente en un programa de rehabilitación de cafetales; en contraste, el primer proyecto solicitado por El Progreso de Amatán, fue autorizado por el director del Centro Coordinador Indigenista de la Región V Norte antes de que esa agrupación obtuviera su registro federal como organización agraria.

Con estos comentarios no se pretende afirmar que la política del INI esté en contra de las organizaciones campesinas autónomas; sin embargo, la experiencia personal como asesor de una organización, me lleva a afirmar que gran parte de la política de apoyo al campo está basada, por un lado, en el otorgamiento de créditos para la producción, sin que exista una verdadera política de capacitación técnica y educativa que no sólo permita al campesino mejorar su productividad, sino que le ayude a alcanzar un mejor nivel de vida; $y$, por otro, en la 
creación de distintos tipos de organizaciones campesinas como uniones de ejidos, sociedades de solidaridad social o cooperativas, que carecen de proyectos a futuro y que son formadas, en muchos casos, para justificar la presencia de las instituciones gubernamentales.

Abundando a este respecto, debe señalarse que las políticas del Estado, y por lo menos a nivel operativo, no toman en cuenta que, en un gran número de casos, el campesino no utiliza el crédito para mejorar su productividad, sino para satisfacer sus necesidades básicas; o bien, que ha sido acostumbrado a no tener que pagar créditos que son utilizados como controles políticos. De hecho, al otorgar préstamos a quienes apoyen al partido oficial, o como justificación del trabajo de las instituciones gubernamentales, se siguen viejas prácticas, sin importar que se tenga o no la capacidad de pagar las deudas; un ejemplo claro de ello es la situación por la que atraviesa la Sociedad de Solidaridad Social El Progreso de Amatán.

Por tanto, a pesar de que el financiamiento es indispensable para el desarrollo rural, debería aplicarse a proyectos agropecuarios afines a las necesidades y características de la vida de los campesinos y de acuerdo con las especificidades de cada región; un proyecto en donde se tome en cuenta a la persona y no sólo a la forma de producir. En síntesis, un proyecto que realmente tienda a mejorar las condiciones de vida de los campesinos, y para lo cual no parece existir voluntad gubernamental.
A pesar de un discurso oficial donde se da un lugar destacado a la autogestión de las organizaciones campesinas, en la práctica las que alcanzan un mayor grado de autonomía son aquellas difíciles de controlar por parte del Estado porque pueden prescindir del trabajo de asesoría técnica del INI, ya que cuentan con equipos de técnicos propios; éstos además, en la mayoría de los casos, tienen un nivel de conocimientos superior al de los técnicos institucionales o bien mantienen un contacto mucho más estrecho con la comunidad, lo cual les permite compenetrarse mejor con sus problemas.

Para concluir, diríamos que, desde un punto de vista personal, las organizaciones campesinas autónomas de tendencia cristiana presentan condiciones favorables para la creación de proyectos de desarrollo de largo plazo, los cuales permitirían mejorar las condiciones de vida en el medio rural. Mi idea está basada en el hecho de que, las personas pertenecientes a este tipo de organizaciones, tienen una visión más informada y crítica de los procesos sociales y económicos que se desarrollan actualmente en el campo mexicano.

De acuerdo con estos planteamientos y tomando en cuenta que en la diocésis de San Cristobal de las Casas existe un número importante de organizaciones con esas características, es posible plantear, como una línea de investigación, un análisis regional de los movimientos sociales chiapanecos que tuviera como base territorial la diócesis que corresponda a su localización, ya que el hecho de pertenecer 
a una en particular (San Cristobal de las Casas, Tuxtla Gutiérrez o Tapachula) imprimirá seguramente características particulares en los movimientos campesinos que se desarrollen en cada una de ellas.

\section{BIBLIOGRAFÍA}

Bartra, Armando, Los berederos de Zapata, Ediciones Era, México, 1986.

-Canabal Cristiani, Beatriz, "El movimiento campesino en la coyuntura actual", La Jornada del Campo, 28 de febrero de 1995.

-CODELIDECH (Comité de Defensa de la Libertad Indígena y Derechos Humanos), Ponencia presentada en Matías Romero, Oaxaca, 1989 (mimeografiado).

-CODELIDECH (Comité de Defensa de la Libertad Indígena y Derechos Humanos), Ponencia presentada en Matías Romero, Oaxaca, 1989 (mimegrafiado).

-Flores Lúa, Graciela, Luisa Paré y Sergio Sarmiento, Las voces del campo. Movimiento campesino y política agraria 1976-1984, Siglo XXI/Instituto de Investigaciones Sociales-UNAM, México, 1988.

-García, Emilio, "Estrategia modernizante y perfil del movimiento campesino contemporáneo", Revista Mexicana de Sociología, año LVI, núm. 2, 1994.

-Gómez Jara, Francisco A., El movimiento campesino en México, Secretaría de la Reforma Agraria, Mexico, 1981.

-Guillén, Diana, "Estructuras tradicionales de poder y modernización política en América Latina", tesis de doctorado, UNAM, México, 1994.
-Hardy, Clarisa, El Estado y los campesinos. La Confederación Nacional Campesina (CNC), CEESTEM/Editorial Nueva Imagen, México, 1984.

-Harvey, Neil, "La lucha por la tierra en Chiapas: estrategias del movimiento campesino" en Sergio Zermeño y Aurelio Cuevas (coord.), Movimientos sociales en México, Centro de Investigaciones Sociales en Humanidades-UNAM, México, 1990. , "La Unión de Uniones de Chiapas y los retos políticos del desarrollo de base", en Julio Moguel et al., Autonomia y nuevos sujetos sociales en el desarrollo rural, Siglo XXI/CEHAM, México, 1991.

-Leyes y Códigos de México, Sociedades mercantiles y cooperativas, $42 \mathrm{ed}$., México, 1988 (Colección Porrúa).

-Marion Singer, Marie Odile, El movimiento campesino en Chiapas 1983, Centro de Estudios del Agrarismo en México, México, 1984.

-Martínez Borrego, Estela y Sergio Sarmiento Silva, "Los estudios actuales sobre los movimientos sociales en el campo", Revista Mexicana de Sociología, año LVI, núm. 2, abril-junio de 1994.

- Mejía Piñeros, María Consuelo y Sergio Sarmiento Silva, La lucha indígena: un reto a la ortodoxia, Siglo XXI, México, 1987.

-Peña Valencia, Gustavo de, "Un tercer actor en el conflicto chiapaneco: las organizaciones campesinas autónomas", $L a$ Jornada del Campo, 22 de febrero de 1994

-Sociedad de Solidaridad Social, "La Flor de Amatán", "Requisitos de ingreso para nuevos socios", 1991 (fotocopias). 